\title{
Potable Water in UAE: An Overview of Water Characteristics and Sources of Contamination
}

\author{
Alaa Abu Shawish", Tasnim Nabhan" and Amer Almadidy* \\ College of Health Sciences, Jumeira University, Dubai, UAE \\ \#Both co-authors would like to be considered as first author \\ *Corresponding author: Amer Almadidy, Director of the College of Health Sciences, College of Health Sciences, Jumeira University, Dubai, \\ UAE, Tel: 045154 547; E-mail: amer.almadidy@ju.ac.ae
}

Received: 11 Feb, 2019 | Accepted: 14 Mar, 2019 | Published: 22 Mar, 2019

Citation: Shawish AA, Nabhan T, Almadidy A (2019) Potable Water in UAE: An Overview of Water Characteristics and Sources of Contamination. J Environ Toxicol Stud 3(2): dx.doi.org/10.16966/2576-6430.120

Copyright: (C) 2019 Shawish AA, et al. This is an open-access article distributed under the terms of the Creative Commons Attribution License, which permits unrestricted use, distribution, and reproduction in any medium, provided the original author and source are credited.

\section{Abstract}

This research aims to provide information about the characteristics of safe drinking water in UAE, identify the causes of water pollution, the treatment process of both wastewater and water, as well as, some sustainability water projects in the UAE.

Using secondary data sources, we've found that UAE's water characteristics are classified into three main categories which are: Physical, chemical and biological characteristics that describe UAE's water using standards and parameters. In addition, it was found that pollutants can affect both groundwater and surface water. The main sources of groundwater contamination are septic tanks effluents, over-pumping of wells, and agricultural activities. On the other hand, the main causes of marine water contamination are increased population and development which lead to increased wastes dumping in water, sediment dredge and fill operations and atmospheric deposition of pollutants. Wastewater treatment in UAE is illustrated by giving Al-Ruwais wastewater treatment plant as an example in where wastewater undergoes screening, aeration, multiple types of filtration and disinfection to produce water suitable for irrigation and some industrial activities. For domestic purposes, water is pretreated, desalinated then enriched with essential minerals. It was found also that UAE has many projects to ensure sustainability as using clean renewable resources for water desalination, harnessing resulting brine to produce salts, completely relying on treated wastewater for industrial and agricultural activities, and projects for decreasing irrigation water demands and carbon footprints as Badia Farms and Porous Alpha technology.

Finally, we recommend using an integrated water protection system where water is protected and controlled in catchments, treatment plants, and distribution systems.

\section{Introduction}

Accessing to safe drinking water is becoming a major issue worldwide, where human contamination, misuse, and overuse of water resources are the main reasons. According to the WHO [1], around 842 thousand people die every year from diarrhea due to the consumption of contaminated water. In the UAE, besides suffering from water scarcity, contamination of these few existing water resources occurred which causes serious problems.

According to Rizk and Alsharhan [2] UAE relies on two types of water, conventional and nonconventional. Conventional resources include seasonal floods, springs, falajes, and groundwater. Prior to 1973, the UAE was dependent on conventional water sources only, but after that year, UAE began to shift to non-conventional water resources by initiating projects which involved the construction of water desalination plants [2] and wastewater treatment plants [3].

The first water desalination plant constructed in Abu-Dhabi in 1973 had a capacity to produce $7 \mathrm{~mm}^{3}$ (million cubic meters) of desalinated water annually. In 1995, 65 desalination plants were constructed all around the Emirates. In 1997, the annual capacity of the production of desalinated water reached $395 \mathrm{~mm}^{3}$ [2]. By 2005, annual production of desalinated water in Abu Dhabi increased to reach 140,100 MIG (million imperialgallons) (Statistics Center Abu Dhabi (SCAD) [4]. However, by 2010, Abu Dhabi's desalinated water production reached 183,561 MIG and by 2017 , it reached 196,848 MIG (1 cubic meter=220 Imperial gallons) (SCAD) [5]. Desalination has removed a considerable burden from conventional freshwater sources, which were scarce in the first place. However, on the other hand, it created a new burden in desalinating the sea water and treating it from any contamination.

While for the sewage treatment plants, the first one was constructed in Abu Dhabi with a capacity of $4000 \mathrm{~m}^{3} /$ day. In 1994, capacity tripled to reach $120,000 \mathrm{~m}^{3} /$ day [2]. In 2013, the capacity of wastewater treatment plants in $\mathrm{AD}$ reached $344.4 \mathrm{~mm}^{3}$ and by 2017 it reached $369.4 \mathrm{~mm}^{3}$ [5]. Therefore, treated wastewater is important in conserving UAE's water in which it's used in some agricultural and industrial activities where the quality of treated water is sufficient and there is no risk to health [2].

UAE has a history of supporting and developing projects that are concerned with the conservation and sustainability of natural 


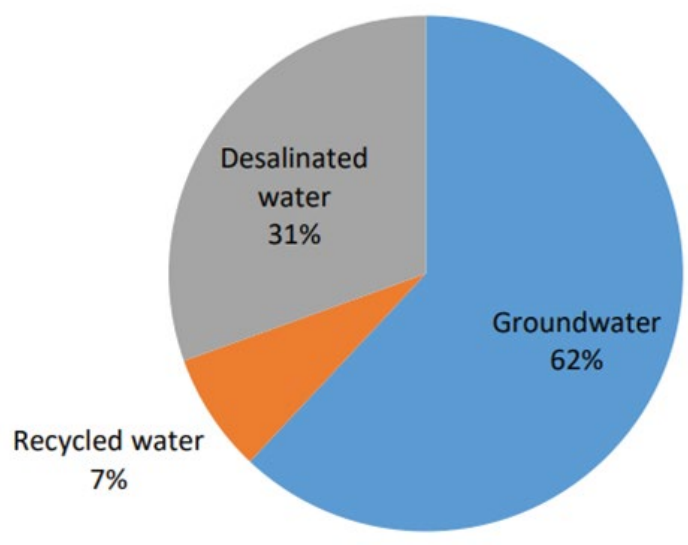

Figure 1: Sources of total water supply in Abu Dhabi in 2012 [12].

resources. In 2002, UAE had initiated a project to conserve groundwater by injecting desalinated water into groundwater aquifers during nonpeak demand. In 2012, UAE was seeking for zero-carbon technology. As part of this vision, Abu Dhabi has constructed 22 solar desalination plants under the supervision of the Environment Agency in Abu Dhabi to improve efficiency, reduce costs and provide information regarding the feasibility of this technology in water desalination sector [6].

Therefore, this paper aims to illustrate UAE's water characteristics, what are the main sources of water contamination, the process of water treatment within the UAE, and finally projects that aim to sustain the water and the environment.

\section{Discussion}

\section{Characteristics of UAE drinking water}

UAE is always striving to provide for its citizen high water quality by putting standards for its treated water. Therefore, according to RSB standards [7], UAE's water characteristics can be classified as the following:

Physical Characteristics: Taste and Odor are characteristics that can be detected by using human senses [8]. Any acidic or basic taste and any smell that is noticed from the water are considered as a violation against UAE's standards of water, where according to their standards, water must be tasteless and odorless. On the other hand, high water turbidity is considered as an indicator of having high amounts of suspended solids in the drinking water, therefore, providing clear water with low turbidity is what UAE seeks for, where the maximum allowed turbidity is 4.0 Nephelometric Turbidity Units (NTU) [7]. While for the residual chlorine, it is defined as the amount of chlorine that remains after a certain period of time of adding the chlorine demand [9]. In the UAE, the acceptable amount of residual chlorine must be between 0.2-0.5 mg/L [7].

Chemical Characteristics: The $\mathrm{pH}$ value of drinking or tap water is categorized under chemical characteristics of the water where this value must be neutral which is around 7 , however, the maximum $\mathrm{pH}$ value accepted in UAE is 9.2. In addition, the presence of some mineral salts in drinking water in limited amounts is beneficial to human; these are called dissolved mineral salts. These mineral salts can be Magnesium, Sodium, Potassium and Iron Salts. In UAE, the maximum concentration of these salts is $30 \mathrm{mg} / \mathrm{L}, 150 \mathrm{mg} / \mathrm{L}, 12 \mathrm{mg} / \mathrm{L}$, and $0.2 \mathrm{mg} / \mathrm{L}$ respectively [7].
Biological Characteristics: In UAE, the presence of total coliform bacteria, E. coli or enterococci is not acceptable at all and their number must be limited to $0 / 100 \mathrm{~mL}$, where any detection of them in a drinking water must be followed by immediate action. However, the presence of other bacteria is also standardized which is 10 bacteria $/ 1 \mathrm{~mL}$ at $37^{\circ} \mathrm{C}$ [7].

\section{Contamination and sources of contamination}

In the last few decades, anthropogenic activities in the UAE increased rapidly due to the development of this country in all its sectors. Consequently, population demands of water increased and contaminating this water became high.

Groundwater pollution: Septic tanks effluents, over-pumping of wells and using fertilizers in the soil are the main reasons for groundwater contamination [10]. According to EPA [11], the presence of septic tanks near groundwater areas may result in outbreaks of waterborne diseases and may cause health problems, since bacteria, viruses, and protozoa can be present in the sanitary wastewater. In addition, sanitary wastewater also contains nitrogen that is mainly from food wastes, feces or from urine, hence, this wastewater may reach the groundwater through the soil and contaminate it.

On the other hand, over-pumping of wells is another source of groundwater contamination. As it is clear in figure 1, in Abu Dhabi Emirate, 62 percent of water supply is taken from groundwater by digging wells [12]. This is an indication of the overuse of groundwater sources which can lead to contamination. According to McDonnel and Fragazsy [12], due to high agriculture practices, some regions in $\mathrm{Al}$ Ain have the greatest decline in groundwater levels. Over-pumping of this groundwater can lead to an increase in arsenic concentration. This was noticed in the San Joaquin Valley of California after a study was done which illustrated the relationship between the over-pumping of groundwater and the raising of arsenic concentration in that region, where they found in that region, over-pumped groundwater contained high concentration of arsenic [13]. Therefore, this is considered contamination of groundwater, which may occur in UAE too.

In addition, a study was conducted in $\mathrm{Al}$ Ain indicated that the presence of some wells near the farming areas, such as Liwa Crescent area, caused nitrate contamination of the groundwater. Since these farming areas use fertilizers and "continuous crops irrigation", this led to nitrate transportation to the nearest aquifers, thus a high concentration of nitrate is present in their groundwater [12].

Marine water pollution: According to Environment AgencyAbu Dhabi (EAD), population growth and associated development are the major causes of marine water pollution. These two elements are responsible for dumping wastes in water. In addition, they are responsible to sediment dredge and fill operations [14] which are "the operation of removing material from one part of the water environment and relocating it to another" [15]. Moreover, increased population and development lead to the increased introduction of polluting materials to the atmosphere which will be precipitated later into water supplies in a process called atmospheric deposition of pollutants. These processes lead to increased nutrients, chemicals and sediments in the marine waters [14]. The main areas of concern in marine water pollution are:

- Eutrophication: The proportion of nutrients in the water, especially phosphorus and nitrogen, are increasing leading to increasing the growth of phytoplankton and algae. This increased growth is associated with oxygen demand which leads to a decreased level of dissolved oxygen, the death of larger aquatic creatures and 


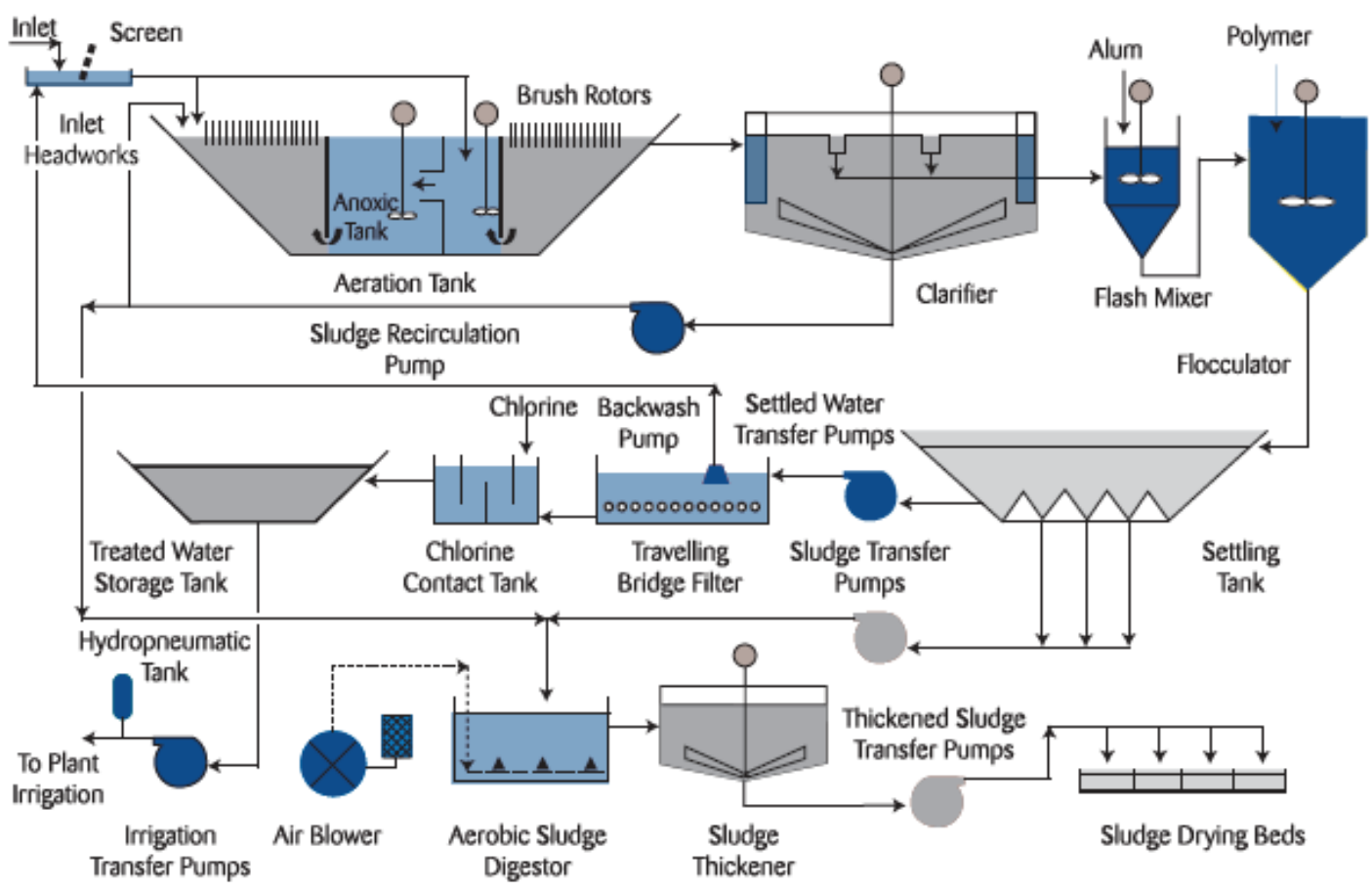

Figure 2: Illustrates wastewater treatment process at Al-Ruwais wastewater treatment plant. It starts with water entering the inlet headworks and ends to treated water storage tank. There are many intermediate processes including aeration, multiple filtration processes and disinfection. Sludge produced during the process is treated, too [17].

reduced level of light that can penetrate the water. The problem of eutrophication mainly occurs because of agricultural runoff which carries agricultural minerals with it [14].

- Harmful algal blooms (HABs): This occurs due to eutrophication and causes the problems mentioned above, in addition to the production of toxins that kill aquatic creatures and the closure of desalination plants [14].

- Bacterial contamination: which results from the discharge of untreated or inadequately treated wastewater into the marine water, agricultural runoff, and stormwater? [14]

- Contaminated sediments: which enter the marine water through industrial and municipal discharges and storm water runoff. These sediments usually contain metals, organic pollutants, and toxins that affect marine organisms and consumers as humans through bio-accumulation of the toxins. In addition to that, aquatic diversity will be reduced [14].

According to EAD marine water quality (MWQ) index in 2016 which is divided into three categories (Eutrophication, microbial and heavy metal index), Eutrophication MWQ was poor in 2016 with a score of 48 and two points away from being considered as fair. On the other hand, Microbial MWQ is good with a score of 99 and one points away from being perfect. Finally, heavy metal MWQ is good with a score of 88 [14].

\section{Wastewater and drinking water treatment in UAE}

Freshwater resources are scarce in UAE and even existing groundwater aquifers are brackish [16]. As a result, the UAE's water resources need to be treated prior to human consumption and activities. Wastewater treatment and drinking water treatment are done in separated plants. One of the new wastewater treatment plants in the UAE is Al-Ruwais Wastewater treatment plant in Abu-Dhabi (Figure 1). The wastewater treatment process starts with collecting sewage from buildings. Collected sewage enters the treatment plant and goes through inlet headworks where grit particles are removed and disposed of then large floating objects are removed through screening. Next, the effluent water is sent to aeration tanks where oxygen is added to water in addition to the presence of anoxic zone in where nitrate is converted into nitrogen gas which escapes from the water in a process called denitrification. After that, the effluent flows to clarifiers where particles settle down forming sludge that pile into a central cone at the bottom of each clarifier. Afterward, effluent undergoes secondary coagulation, flocculation, and sedimentation. In this step, positively charged particles [usually Aluminum polymers] are added to the wastewater to attract negatively charged particles and dust in the water and neutralize them, forming flocs by mixing the effluent with the added particles rapidly by the flash mixer. The resulting large particles will be sent to settling tanks to form sediments. Next, the effluent is pumped to traveling bridge gravity filters to enhance its quality. These filters contain backwash equipment, which removes particulates and clogs, and resulting backwashing water is pumped again to the inlet headworks to be treated. After the effluent underwent gravity filtration, it's sent to chlorine contact tank for disinfection. Finally, treated wastewater is sent to the treated water storage tank to be used later for irrigation [17].

Sludge produced through treatment process from clarifiers and sedimentation is pumped to aerobic digestion tank where it's digested 
under aerobic conditions. After aerobic sludge digestion, digested sludge is pumped to sludge thickener tank then to sludge drying beds where sludge is dried and the resulting supernatant water is sent again to the inlet headworks to be treated [17].

To produce drinking water, seawater is pumped into water desalination plants. The water is pretreated to meet water quality standards in the UAE, and then the water undergoes desalination. 90\% of Gulf's desalinated water is produced through thermal desalination where water is evaporated then condensed to separate evaporated fresh water from precipitated brine. On the other hand, only $6 \%$ of desalinated water in the gulf is produced through reverse osmosis in which water is forced to pass through a semi-permeable membrane that allows the passage of water molecules only, leaving the brine behind [18]. Despite desalinated water is safe water but it lacks the minerals required for the maintenance of human health. As a result, Limestone is added to water to provide the water with necessary minerals [19] (Figure 2).

\section{UAE projects for water \& environmental sustainability}

UAE is one of the leading cities in the field of environmental protection and sustainability innovations and initiatives. To reduce the impacts on the environment due to the desalination process, UAE plans to substitute fossil fuel with clean, renewable energy sources like solar and nuclear energy [16]. Masdar Renewable Energy Desalination Program is testing for new solutions to desalinate water through solarpowered reverse osmosis, which is $75 \%$ more efficient than thermal desalination [20]. UAE also is looking for a way to use resulting brine to produce salts. To preserve the already scarce freshwater sources, the UAE is planning to rely completely on treated wastewater for activities other than domestic uses and to allocate desalinated water for human consumption. According to Abu Dhabi Municipality, by 2030 the plan is to completely rely on treated sewage effluent [16]. Another innovative project to reduce water used for irrigation is Badia Farms in Dubai. These farms use hydroponic technology in which mineral solution replaces soil to grow the plants. This project saves $90 \%$ of water used in open-field farming and minimizes carbon footprint. Besides, these farms consume minimal recycled water and are free of chemicals, herbicides, and pesticides. Furthermore, a new solution originated by a UAE-Japanese partnership where Porous Alpha technology is used to adjust the soil, save $50 \%$ of water consumption in agriculture, increase crops yield by $20 \%$, reduce energy requirements for desalination and reduce $\mathrm{CO}_{2}$ emissions [19].

\section{Recommendations}

To ensure water quality, we recommend the protection and control of the catchments to protect those who consume or use the water at its main sources and to make the treatment process more efficient. Besides, we recommend periodic maintenance of pipelines and reservoirs to prevent leaks and contamination [21]. In addition, we recommend periodic inspection of water facilities and imposing fines and penalties on those who violate the rules. Finally, we encourage projects that offer solutions to water problems and focus on sustainability and efficiency. In addition, we recommend that these projects be easy to implement and encourage targeted facilities and industries to implement them.

\section{Conclusion}

To sum up, water in the UAE has high-quality standards for each of the physical, chemical and biological characteristics. There are many sources of water contaminants that impact both, surface marine water and groundwater. Both types can be polluted through natural sources of pollution; however, human activities pose the greatest risk. Groundwater can be polluted mainly through septic tanks effluents, over-pumping of wells and using fertilizers in the soil. On the other hand, marine water can be polluted through the introduction of chemicals, sediments, and minerals through dumping wastes, sediment dredge and fill operations and atmospheric deposition of pollutants. Groundwater and marine water can be treated in desalination plants to produce drinking water and water for domestic uses. On the other hand, sewage effluent can be treated in special wastewater treatment plants to produce treated wastewater that can be used for agricultural and some industrial activities. UAE has several projects concerned with desalinating water using renewable energy sources to run reverse osmosis desalination processes. Other projects are concerned with harnessing brine to produce salts and making crops irrigation more efficient and producing fewer carbon products.

\section{References}

1. WHO (2018) Drinking-Water: Access to Water.

2. Rizk Z, Alsharhan A (2003) Water resources in the United Arab Emirates. Developments in Water Sci 50: 245-264.

3. Alwathba, Veolia, Besix (n.d.) History of wastewater treatment in Abu Dhabi.

4. Statistics Center Abu Dhabi (SCAD) (2009). Statistical year book of Abu Dhabi 2009. Statistical Year books. Abu Dhabi: SCAD 115.

5. Statistics Center Abu Dhabi (SCAD) (2018) Statistical yearbook of Abu Dhabi 2018. Statistical Year books. Abu Dhabi: Statistics Center Abu Dhabi 312.

6. Environment Agency-Abu Dhabi (EAD) (2012) Annual report 2012. Annual reports, Abu Dhabi: EAD 27-28.

7. RSB (2014) The Water Quality Regulations. $4^{\text {th }}$ edition, The Regulation and Supervision Bureau. 41-45.

8. Arora P (2018) Physical, Chemical and Biological Characteristics of Water. Environ Sci 3: 4-16.

9. ALS (2012) Residual Chlorine Technical Data sheet. ALS Environmental Ltd 44: 1-2.

10. Fanack (2017) Water Quality in UAE, Fanack Water.

11. EPA (2001) Source Water Protection Practices Bulletin Managing Septic Systems to Prevent Contamination of Drinking Water, EPA 21: 1-3.

12. McDonnel R, Fragaszy S (2016) Groundwater Use and Policies in Abu Dhabi', IWMI Project Report 13: 7-10.

13. Smith R, Knight R, Fendorf S (2018) Overpumping leads to California groundwater arsenic threat. Nat Commun 9: 1-6.

14. Environment Agency-Abu Dhabi (EAD) (2016) Marine water quality. Annual summary report. Abu Dhabi: EAD.

15. European Dredging Association (EuDA) (n.d.) Dredging.

16. Export (2018) UAE-water. Export: UAE.

17. Metito (2015) Wastewater treatment plant for Ruwais Housing Complex Abu Dhabi-UAE.

18. Landais E (2009) Desalination: facts and procedures. Gulf News.

19. Simpson C (2013) UAE's largest power and desalination plant open at Jebel Ali.

20. Stanley I (2018) How the UAE secures its future water needs. Gulf News.

21. WHO (2017) Guidelines for drinking-water quality. WHO: Geneva. 